\title{
Initial approach to patients with acute lower back pain
}

\author{
Andrel Fernandes Joaquim ${ }^{1 *}$ \\ ${ }^{1}$ PhD - Neurosurgeon, Universidade Estadual de Campinas (Unicamp), Campinas, SP, Brazil
}

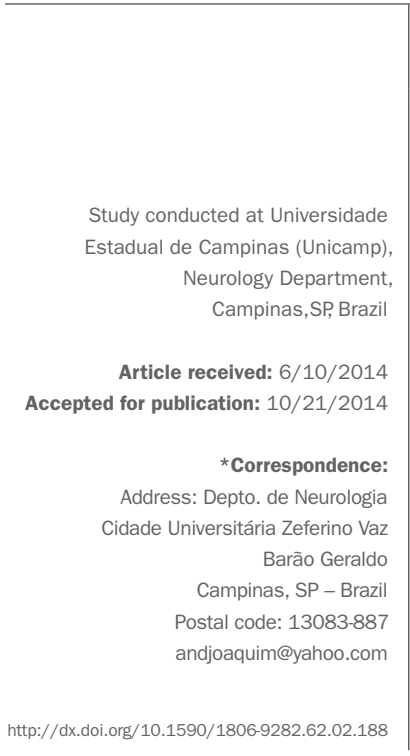

\section{INTRODUCTION}

Acute low back pain is defined as low back pain of less than 6 weeks, experienced between the rib cage and buttocks and which may or may not radiate into the legs. Usually, it starts after waking or after a specific movement, such as carrying weight, leaning, or sitting or standing up suddenly. ${ }^{1}$ The pain generally worsens with movement of the muscles in the lower back. Low back pain is also known as nonspecific when it cannot be assigned to known causes; that is, defined conditions such as infection, osteoporosis, tumors, ankylosing spondylitis, fractures, inflammation or nerve compression. ${ }^{1}$ Non-specific pain possibly results from an exaggerated and sustained muscle spasm.

Epidemiologically, acute low back pain is one of the most common reasons for seeking medical care in emergency units, and is the second leading cause of work absence. ${ }^{2,3}$ It is estimated that about $40 \%$ of low back pain are work-related, with probable variations by region, level of economic development of the country, and the occupation of workers. ${ }^{4}$ Approximately $30 \%$ of patients with acute back pain will not be fully recovered in 6 months and may develop chronic pain or recurrent episodes of low back pain (LBP), which emphasizes the importance of diagnosis. ${ }^{3}$

Although the causal relationship is questionable, some risk factors should be pointed out such as the work dependent on vigorous physical activity, repetitive move- ments and which demand paraspinal muscles (getting up and down, bending, etc.), exposure to vibration, prolonged static postures, and more. Psychosocial risk factors can also often be found in these patients, such as job dissatisfaction, depression, anxiety, excessive stress, cognitive dysfunction. ${ }^{5}$

Given its economic and social importance, the proper management of these patients in emergency care units or offices is of fundamental importance. Treatment of acute low back pain aims to reduce pain, improve function and prevent the progression to recurrent or chronic pain.

\section{Key points in the INITIAL APPROACH}

1. Identify severe causes of low back pain that require specific treatment - identify the "red flags" or signs of severe underlying disease, such as fractures, tumors or infections.

2. Rule out differential diagnoses - urological or gastrointestinal disease, etc.

3. Identify potential root compression and neurologic deficits.

Red flags

The basic principles of proper history-taking followed by comprehensive physical examination are crucial for initial management of any disease. Although uncommon, severe 
diseases that require specific intervention by specialists can be identified in the initial assessment. The presence of red flags increases the chances of underlying disease, which can result in patient referral to a specialist. Causes that should be ruled out primarily include spinal fractures, canda equina syndrome, tumors and infections. ${ }^{1}$

As for items that should be investigated during the history-taking, the most important are: history of cancer, especially in cases of bone involvement, recent rapid weight loss, urinary incontinence or retention, prolonged use of corticosteroids, osteoporosis, extremes of age (> 70 years), fever, previous back surgery, major trauma, weakness or loss of strength in the legs. Obviously, according to clinical criteria, other issues may be raised and analyzed on a case-by-case basis.

Henschke et al. evaluated 1,172 patients consecutively seen in basic units for acute low back pain. ${ }^{6}$ Of the total, there were only 11 cases with serious underlying disease $(0.9 \%$ of the total), of which 8 were spinal fractures. Among the red flags associated with serious diseases, chronic steroid use, age over 70 years and significant trauma history were the most important. The authors emphasize that the presence of isolated red flags was common, which was not predictive of disease.

\section{Physical examination}

Commonly, local pain on palpation secondary to muscle spasms are often documented. It gets worse when the patient bends down, performs extensions or bends.

Evaluation of neurological deficits is essential, with assessment of the strength in the lower limbs. The pain may radiate into the legs or thighs. Root compression results in severe pain in the legs, which may even be stronger than the low back pain. L1 to L3 root compression, although less common, occurs with pain in the hips and/ or thighs, while L4-L5-S1 compression occurs with pain in the posterior thigh and leg, reaching all the way to the foot, which is called sciatica pain. The Lasègue signal, also known as straight leg raise referring to the elevation of the stretched leg, results in worsening of nerve root compression at L4-L5-S1, with worsening of the pain. Sciatica pain is caused by disc herniation in most cases. The evaluation of muscle strength is essential. Hip flexion (L2), knee extension (L3), ankle dorsiflexion (L4), thumb extension (L5) and plantar flexion of the foot (S1) are examined. The presence of neurological deficit, such as decreased muscle strength, requires neurosurgical evaluation if there is any need for immediate surgical treatment. ${ }^{1}$

Sensitivity should be appraised, especially if there is a complaint of changes in the perineal area, as it can be associated with cauda equina syndrome - massive herniation of intervertebral disc occurring with compression of multiple roots sphincter dysfunction, which leads to urinary and fecal retention commonly associated with bilateral sciatica pain. When there is suspicion of sphincter dysfunction, evaluation of sphincter sensitivity and tone is critical.

\section{Radiological ASSESSMENT}

For the vast majority of patients with acute low back pain, the initial radiological evaluation is not required, especially when there is no evidence of a serious underlying disease during history-taking and physical examination, given the benign and, generally, limited nature of the problem. ${ }^{7,8}$ In suspected cases of more aggressive disease, although plain X-rays are widely available and can diagnose fractures, radiographs have low diagnostic sensitivity and specificity compared with magnetic resonance imaging, which is the method of choice as it allows excellent evaluation of bones, ligaments and neural components of the spine. If not available, computed tomography image reconstruction can be used. Physicians must be aware that adult and elderly patients may have degenerative problems that must be correlated with the clinical picture in order to avoid misinterpretation of imaging findings.

\section{LABORATORY TESTS}

Laboratory tests are of little use in most cases but may play a role in suspected spinal infection (primary or postoperative discitis) with complete blood count tests, blood cultures and evidence of inflammatory activity. They may also be useful in the differential diagnosis, as in the assessment of urine to rule out nephrolithiasis, or amylase in suspected pancreatitis. ${ }^{1}$

\section{Differential diagnoses}

- Nephrolithiasis/pyelonephritis: Pain radiating to the genitals or perineum, in the anterior groin area. Giordano signal present, signs of change in urinary habits (frequency, smell, dysuria).

- Abdominal aneurysm: Pulsatile mass in the abdomen, abdominal pain radiating into the lower back.

- Pancreatitis/stomach and gallbladder disease: Abdominal pain, food-related discomfort, vomiting, pain radiating into the lower back.

- Pelvic diseases: Perineal discomfort, discharge, pain on palpation of the area.

- Hip diseases: Pain on movement of the hip joint, restriction of hip movement. 


\section{TREATMENT}

\section{Patient advice}

Advising the patient that the pain is benign and transient is important because the intensity of pain can result in great psychological impact on patients.

Recommendations are individualized, but bed rest should be avoided, with return to normal activity as soon as there is pain relief. ${ }^{9,10}$ Efforts that require excessive movement of the spine should be avoided such as moving up and down, prolonged postures, repetitive movements and physical activity if there is pain.

Applying local heat can be helpful, but ice is not recommended. ${ }^{11}$

\section{Medication}

Plain analgesic drugs such as acetaminophen and nonsteroidal anti-inflammatory drugs (NSAIDs) are effective and recommended for pain control. There is evidence that NSAIDs are first-line drugs for pain control. ${ }^{12}$

Nonbenzodiazepine muscle relaxants can be prescribed in the treatment of acute pain. These drugs should be used with caution especially in the elderly because they may cause dizziness and drowsiness, increasing the risk of falls. ${ }^{13}$ Diazepam and carisoprodol should also be used with caution due to risk of addiction.

Opioids can be used in cases of severe pain, also with caution, for the shortest time required, usually less than two weeks. ${ }^{14}$

The physician should always inform the patient of the possible side effects of each drug class, as well as consider probable drug interactions.

\section{Controversial treatments}

The use of orthotics, such as jackets, is not recommended as routine in the treatment of acute low back pain due to a real difficulty to immobilize the spine and lack of scientific studies that support their use. ${ }^{15}$

Acupuncture, massage and spinal manipulation need more evidence to be recommended as a treatment in the acute phase of low back pain. ${ }^{13}$

The use of oral or injectable corticosteroids is not recommended as routine in the treatment of acute low back pain. ${ }^{16}$

\section{Recurrence}

Although the recommendations for exercise and physical therapy in episodes of acute pain vary in the literature, physical practice should be avoided at an early stage as it usually causes exacerbation of pain. However, the promotion of physical activities as soon as the patient's symp- toms have improved, with muscle strengthening and stretching, improves the overall physical condition and is recommended. Weight loss is also indicated. ${ }^{13}$

Glotle et al. evaluated a series of 123 patients with acute low back pain (less than 3 weeks duration) for the first time. ${ }^{17}$ Of these, 120 patients were reassessed after 3 months of follow-up. The authors found that between 1 and 3 months, $76 \%$ of patients had recovered. As poor prognostic factors, they found that age over 45, smoking habit, signs of neurological disorder and high levels of stress at presentation were associated with non-recovery of patients, characterizing the disease as multifactorial. They suggested that a psychological approach should be taken in conjunction with the treatment of pain in these patients, since $24 \%$ were not fully recovered in 3 months.

Although the nature of pain is benign and self-limiting in general, patients who do not recover in three months tend to have chronic mild to moderate pain after a year. ${ }^{18}$ Most patients experience symptom improvement after one month, but the 1-year recurrence rate is high - about two thirds of patients with an episode of acute low back pain will have another in the following 12 months. ${ }^{19}$ Improvement is progressive and usually takes two to four weeks.

Encouraging changes in lifestyle, healthy habits and physical activity, as well as dietary changes to prevent weight gain and promote health, is essential to avoid relapses.

\section{Resumo}

Abordagem inicial do paciente com lombalgia aguda

A dor lombar é uma das causas mais comuns de procura à assistência médica em unidades de pronto atendimento. É ainda a segunda causa de afastamento laboral. O reconhecimento de sinais de alerta de doenças graves, como tumores e fraturas, por meio de anamnese e adequado exame clínico, é fundamental para o adequado tratamento e a exclusão de diagnósticos diferenciais. Na ausência de suspeita de doença grave subjacente, exames radiológicos subsidiários são desnecessários. O uso de analgésicos e anti-inflamatórios é o tratamento de primeira escolha, podendo estar associado a relaxantes musculares e opioides, com cautela em casos mais graves. A maior parte dos pacientes apresentará melhora total dos sintomas após alguns meses; porém, uma minoria irá desenvolver lombalgia crônica ou quadros recorrentes. $\mathrm{O}$ adequado entendimento de todos esses pontos permite otimizar resultados e evitar erros diagnósticos e terapêuticos.

Palavras-chave: dor lombar, tratamento de emergência, diagnóstico. 


\section{References}

1. Casazza BA. Diagnosis and treatment of acute low back pain. Am Fam Physician. 2012; 85(4):343-50.

2. Deyo RA, Tsui-Wu YJ. Descriptive epidemiology of low-back pain and its related medical care in the United States. Spine (Phila Pa 1976). 1987; 12(3):264-8.

3. Carey TS, Garrett J, Jackman A, McLaughlin C, Fryer J, Smucker DR. The outcomes and costs of care for acute low back pain among patients seen by primary care practitioners, chiropractors, and orthopedic surgeons. The North Carolina Back Pain Project. N Engl J Med. 1995; 333(14):913-7.

4. Punnett L, Prüss-Utün A, Nelson DI, Fingerhut MA, Leigh J, Tak S, Phillips S. Estimating the global burden of low back pain attributable to combined occupational exposures. Am J Ind Med. 2005; 48(6):459-69.

5. Andersson GBJ. The epidemiology of spinal disorders. In: Frymoyer JW (ed.) The adult spine: principles and practice. 2.ed. New York: Raven Press, 1997. p.93-141.

6. Henschke N, Maher CG, Refshauge KM, Herbert RD, Cumming RG, Bleasel $\mathrm{J}$, et al. Prevalence of and screening for serious spinal pathology in patients presenting to primary care settings with acute low back pain. Arthritis Rheum. 2009; 60(10):3072-80.

7. Chou R, Qaseem A, Owens DK, Shekelle P; Clinical Guidelines Committee of the American College of Physicians. Diagnostic imaging for low back pain: advice for high-value health care from the American college of physicians. Ann Intern Med. 2011; 154(3):181-9.

8. French SD, Green S, Buchbinder R, Barnes H. Interventions for improving the appropriate use of imaging in people with musculoskeletal conditions. Cochrane Database Syst Rev. 2010; (1):CD006094.
9. Hagen KB, Hilde G, Jamtvedt G, Winnem M. Bed rest for acute low-back pain and sciatica. Cochrane Database Syst Rev. 2004; (4):CD001254.

10. Dagenais S, Tricco AC, Haldeman S. Synthesis of recommendations for the assessment and management of low back pain from recent clinical practice guidelines. Spine J. 2010; 10(6):514-29.

11. French SD, Cameron M, Walker BF, Reggars JW, Esterman AJ. Superficial heat or cold for low back pain. Cochrane Database Syst Rev. 2006; (1):CD004750.

12. Roelofs PD, Deyo RA, Koes BW, Scholten RJ, van Tulder MW. Non-steroidal anti-inflammatory drugs for low back pain. Cochrane Database Syst Rev 2008; (1):CD000396.

13. van Tulder MW, Touray T, Furlan AD, Solway S, Bouter LM. Muscle relaxants for non-specific low back pain. Cochrane Database Syst Rev. 2003; (2):CD004252

14. Cifuentes M, Webster B, Genevay S, Pransky G. The course of opioid prescribing for a new episode of disabling low back pain: opioid features and dose escalation. Pain. 2010; 151(1):22-9.

15. Zarghooni K, Beyer F, Siewe J, Eysel P. The orthotic treatment of acute and chronic disease of the cervical and lumbar spine. Dtsch Arztebl Int. 2013; 110(44):737-42

16. Eskin B, Shih RD, Fiesseler FW, Walsh BW, Allegra JR, Silverman ME, et al Prednisone for emergency department low back pain: a randomized controlled trial. J Emerg Med. 2014; 47(1):65-70.

17. Grotle M, Brox JI, Veierød MB, Glomsrød B, Lønn JH, Vøllestad NK. Clinical course and prognostic factors in acute low back pain: patients consulting primary care for the first time. Spine (Phila Pa 1976). 2005; 30(8):976-82.

18. Heuch I, Foss IS. Acute low back usually resolves quickly but persistent low back pain often persists. J Physiother. 2013; 59(2):127.

19. Pengel LH, Herbert RD, Maher CG, Refshauge KM. Acute low back pain: systematic review of its prognosis. BMJ. 2003; 327(7410):323. 